Meeussen, K., Block, L. van den, Echteld, M.A., Boffin, N., Bilsen, J., Casteren, V. van, Abarshi, E., Donken, G Onwuteaka-Philipsen, B., Deliens, L. End-of-life care and circumstances of death in patients dying as a result of cancer in Belgium and the Netherlands: a retrospective comparative study. Journal of Clinical Ondälby 2011, 29(32), 4327-4334

\begin{tabular}{|l|l|}
\hline Postprint Version & 1.0 \\
\hline Journal website & $\underline{\text { http://jco.ascopubs.org/content/29/32/4327.long }}$ \\
\hline Pubmed link & $\underline{\text { http://www.ncbi.nlm.nih.gov/pubmed/21990415 }}$ \\
\hline DOI & $10.1200 /$ JCO.2011.34.9498
\end{tabular}

This is a NIVEL certified Post Print, more info at http://www.nivel.eu

\title{
End-of-Life Care and Circumstances of Death in Patients Dying As a Result of Cancer in Belgium and the Netherlands: A Retrospective Comparative Study
}

\author{
Koen Meeussen, Lieve Van den Block, Michael A. Echteld, Nicole Boffin, Johan Bilsen,

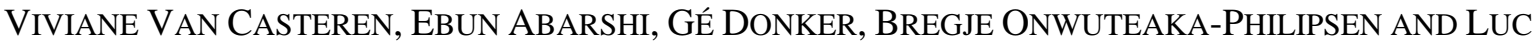 \\ DELIENS
}

\begin{abstract}
Purpose To examine and compare end-of-life care in patients with cancer dying in Belgium and the Netherlands.

Patients and Methods A mortality follow-back study was undertaken in 2008 via representative nationwide sentinel networks of general practitioners (GPs) in Belgium and the Netherlands. By using similar standardized procedures, GPs reported on aspects of end-of-life care and the circumstances of nonsudden death of patients with cancer in their practice.

Results Of the 422 reported patients with cancer, most resided at home during the last year of life (Belgium, 91\%; the Netherlands, 95\%). Death occurred at home in 34\% (Belgium) and 61\% (the Netherlands) and in the hospital in 29\% (Belgium) and 19\% (the Netherlands). In the last month of life, end-of-life issues were more often discussed in the Netherlands (88\%) than in Belgium (68\%). In both countries, physical problems were discussed most often (Belgium, 49\%; the Netherlands, 78\%) and spiritual issues least often (Belgium, 20\%; the Netherlands, $32 \%$ ). Certain end-of-life treatment preferences were known for $43 \%$ (Belgium) and $67 \%$ (the Netherlands) of patients. In the last week of life, treatment was most often focused on palliation (Belgium, 94\%; the Netherlands, 91\%). Physical distress was reported in $84 \%$ (Belgium) and 76\% (the Netherlands) of patients and psychological distress in 59\% and 36\%. Most distressing was lack of energy (Belgium, 73\%; the Netherlands, 71\%) and lack of appetite (Belgium, 61\%; the Netherlands, 53\%). Two thirds of patients were bedridden (Belgium, 67\%; the Netherlands, 69\%).

Conclusion Although place of death and communication about end-of-life issues differ substantially, a palliative treatment goal is adopted for the vast majority of patients in both countries. However, GPs reported that the majority of patients experienced symptom distress at the end of life, which suggests important challenges remain for improving end-of-life care.
\end{abstract}

\section{INTRODUCTION}

Cancer therapy is successful for many patients with cancer. However, in advanced cancer, cure or prolonging life may no longer be possible, and palliative care becomes the only realistic treatment option. Palliative care is aimed at improving the quality of life of patients and their families by providing relief from physical, psychological, and spiritual problems. ${ }^{1}$ Although palliative care is well developed for patients suffering from cancer, ${ }^{2}$ there is consensus that further improvement is still possible and needed. ${ }^{3,4}$ 
Although large-scale studies demonstrate that many patients with cancer die at home, ${ }^{5,6}$ much information on end-of-life care and circumstances of dying for patients with cancer is often gathered from studies focusing on specific institutional care settings. ${ }^{7-13}$ To gain better insight into the care and the manner of dying of the total population of patients with cancer, nationwide studies irrespective of care setting or type of cancer are needed.

In both Belgium and the Netherlands, the existing nationwide representative networks of general practitioners (GPs) can be used to meet these goals. Since the provision of palliative care in both countries is often coordinated by the GP, almost all inhabitants have their own GP, ${ }^{14,15}$ and GPs are involved in endof-life care in virtually all patients with cancer. ${ }^{16}$ This sentinel GP network has been used successfully in the past to study aspects of end-of-life care in both countries, ${ }^{17-23}$ but studies have never focused specifically on patients dying as a result of cancer.

Identical study designs were used in both countries, which provides an important opportunity to perform cross-national comparisons. In both Belgium and the Netherlands, there is a high level of accessibility to general health care services and a policy of integration of palliative care into the national health care system, ${ }^{24}$ but there are also important differences, making comparisons particularly relevant. Although Belgium has chosen to place multidisciplinary teams into different care settings, the Netherlands focuses more on the promotion of palliative care skills among regular caregivers supported by consultation teams. ${ }^{25}$ GPs in the Netherlands act as absolute gatekeepers to more specialized care by being the patient's first contact with the health care system and controlling access and referrals to specialists' services and clinicians. In addition, there are specialized nursing homes in the Netherlands but not in Belgium. ${ }^{26}$

The main objectives of this study are to describe the end-of-life care and circumstances of death of patients dying as a result of cancer in Belgium and the Netherlands and to make comparisons between the countries.

\section{PATIENTS AND METHODS}

\section{Study Design}

This study is an analysis of 1-year (2008) data collection within the Senti-Melc study, a study designed to monitor retrospectively the end of life of patients via existing national sentinel networks of general practitioners in Belgium and the Netherlands. ${ }^{27}$ In both countries, these networks of GPs are reliable surveillance systems with a long history of nationwide surveillance of a wide variety of health-related topics that use similar standardized procedures of data collection. ${ }^{27-33}$ In the past, several of the registrations (eg, stroke mortality, suicide incidences, place of death, care setting trajectories) have been compared with data from external resources and have resulted in good external validity of the sentinel network's registrations. ${ }^{28,34-36}$

In 2008, the Belgian network comprised 172 regularly participating practices compared with 45 in the Netherlands, each covering approximately $1 \%$ to $2 \%$ of the total registered patient population in each country and representative of GPs nationwide by sex, age, and geographic distribution. ${ }^{37,38}$

Participating GPs were asked to fill in retrospectively a standardized registration form for all deaths at age 1 year or more in their practice covering the dying process and the care received during the last months of life. In Belgium, GPs reported deaths on a weekly basis; in the Netherlands, because GP patient lists are registered centrally, the registration form was sent to them by the Netherlands Institute of Health Services Research within 1 week of receipt of an electronic death notice. When necessary, reminders were sent.

Patients dying as a result of cancer were identified by a question about the underlying cause of death. Those who had died totally unexpectedly and suddenly, as judged by the GP, were excluded from further analysis since our focus was on those patients with cancer for whom the provision of end-of-life care was a relevant consideration. ${ }^{20-22}$ All data were reported directly by the GP.

\section{End-of-Life Care Setting and the GP}

In both countries, the main settings for receiving end-of-life care and for dying are home, hospital, hospice or palliative care unit, and care home. In the Netherlands, there is a structural distinction between residential homes and nursing homes. Although both provide long-term home replacement care, residential homes provide basic assistance to older people who can no longer live independently under the care of the 
Meeussen, K., Block, L. van den, Echteld, M.A., Boffin, N., Bilsen, J., Casteren, V. van, Abarshi, E., Donken, G Onwuteaka-Philipsen, B., Deliens, L. End-of-life care and circumstances of death in patients dying as a result of cancer in Belgium and the Netherlands: a retrospective comparative study. Journal of Clinical Ondably 2011, 29(32), 4327-4334

GP, although nursing homes provide more specialized geriatric care by specialist nursing home physicians. ${ }^{39}$ In Belgium, the GP is responsible for the care of both kinds of care home residents. ${ }^{21}$

\section{Measurements}

Several comprehensive conceptual frameworks on quality of end-of-life care exist, some specifically for patients with cancer. ${ }^{3,40-51}$ On the basis of these models, we identified the following key domains of end-oflife care: medical care processes, communication processes, and circumstances of dying (Table 1 provides an overview of the topics surveyed). Most questions had been developed and pretested in previous research. ${ }^{20,21,23,27,52-56}$

\section{[TABLE 1.]}

Several procedures were used to ensure data quality: collective development and pretesting of the registration form in both countries, automatic follow-up (in Belgium), and telephone contact with the GPs to prevent missing data and ensure data entry with range, consistency, and skip checks. Methodologic details are described elsewhere. ${ }^{27}$

\section{Data Analysis}

Percentages were used to describe the proportion of patients with cancer for whom different aspects of end-of-life care were provided. Fisher's exact tests were used to determine which aspects of the dying process or the care received at the end-of-life were associated with residing in either Belgium or the Netherlands $(P<.05)$. Associations were further explored in multivariate logistic regression analyses while adjusting for differences in place of death (because of the relationship with GP involvement and country), age, and sex, unless stated otherwise. Possible interaction effects were determined between these patient characteristics and the patient's country. In the tables, we display the odds ratios (ORs) in cases in which a relevant country effect was found.

To investigate the representativeness of the data for all nonsudden cancer deaths in Belgium and the Netherlands, we compared age, sex, and place of death of our sample with numbers identified in previous nationwide representative death certificate studies in both Belgium (Flanders; comparison data were not available for the French-speaking part of Belgium ${ }^{57}$ and the Netherlands. ${ }^{58}$ In Belgium, no significant differences between studies were found for these characteristics (multinomial 95\% CI). In the Dutch part of the sample, nursing home deaths were underrepresented, which was to be expected since nursing home physicians take over care from the GP. After leaving out these deaths, representativeness was reached. We used SPSS 17 (SPSS, Chicago, IL) and StatXact6 (Cytel Studio, Cambridge, MA) for statistical computations.

\section{RESULTS}

\section{Characteristics of Patients}

The Belgian and Dutch GPs reported 1,354 and 405 deaths, respectively. We excluded all patients who had died suddenly (35\%; $n=616$ ) leaving 1,143 patients. For 422 of these (37\% in each country), cancer was reported as the underlying cause of death. The majority of patients in both countries resided at home during the last year of life (Belgium, 95\%; the Netherlands, 91\%; Table 2). Place of death was the only characteristic that was strongly associated with country $(P<.001)$, with more hospital deaths in Belgium $(29 \% v 19 \%)$ and more deaths at home in the Netherlands (59\% v 34\%).

\section{[TABLE 2. ]}

\section{Medical Care Processes at the End of Life}

During the last 3 months of life, 38\% of Belgian and 56\% of Dutch patients had more than eight contacts with their GP $(P=.001$; Table 3); $66 \%$ of Belgian and $44 \%$ of Dutch patients were transferred to another care setting $(P<.001)$, and $72 \%$ of Belgian and $34 \%$ of Dutch patients used palliative care services $(P<$ $.001)$. 
Meeussen, K., Block, L. van den, Echteld, M.A., Boffin, N., Bilsen, J., Casteren, V. van, Abarshi, E., Donken, G Onwuteaka-Philipsen, B., Deliens, L. End-of-life care and circumstances of death in patients dying as a result of cancer in Belgium and the Netherlands: a retrospective comparative study. Journal of Clinical Ondably 2011, 29(32), 4327-4334

\section{[TABLE 3. ]}

During the last week of life, contact with the GP was maintained by $71 \%$ of Belgian and $87 \%$ of Dutch patients $(P=.001)$, and the treatment goal was palliation and not cure or prolonging life in $94 \%$ of Belgian and $91 \%$ of Dutch patients $(P=.372)$.

Multivariate analyses showed that variations in the use of palliative care services (more in Belgium; OR, 6.73), the proportion of patient-GP encounters in the last week of life (more in the Netherlands; OR, 0.48), and hospital deaths (more in Belgium; OR, 1.89) remained statistically significant after controlling for differences in patient characteristics.

\section{Communication Processes at the End of Life}

Before the last month of life, 74\% (Belgium) and 71\% (the Netherlands) of patients who died as a result of cancer had discussed one or more end-of-life care issues with their GP $(P=.695$; Table 4). Primary diagnosis, incurability of the illness, and physical symptoms were discussed most frequently in both countries, and spiritual issues were discussed least frequently.

\section{[TABLE 4.]}

During the last month of life, $68 \%$ (Belgium) and $88 \%$ (the Netherlands) of patients had discussed one or more end-of-life care issues with their GP $(P<.001)$. In Belgium, less than a third had talked about spiritual issues, social problems, the burden of treatments, primary diagnosis, possible medical complications, or life expectation. Other issues were discussed more often but never by more than half the patients. In the Netherlands, only discussion of spiritual issues was rare, whereas all other topics were discussed by at least half the patients and most frequently concerned life expectation, options for palliative care, and physical problems. All differences between countries, except for spiritual issues, remained significant in the multivariate analyses after controlling for differences in age, sex, and place of death. After additionally adjusting for number of patient contacts during the last month of life (to evaluate whether contact frequency would explain differences in communication), significance was maintained.

About half (54\%) of Belgian and 73\% of Dutch patients expressed a preference for place of death ( $P=$ .001 ), and $43 \%$ of Belgian and $67 \%$ of Dutch patients had at some point expressed a wish concerning medical end-of-life treatment $(P<.001)$. After adjustment for differences in age, sex, and place of death, country remained associated with the prevalence of a preference for end-of-life treatment (more in the Netherlands; OR, 0.40).

\section{Circumstances of Dying}

During the last week of life, about two thirds of patients with cancer in Belgium (67\%) and the Netherlands (69\%) were completely physically disabled and bedridden $(P=.712$; Table 5$)$. Physical distress was reported in $84 \%$ of the patients in Belgium and in $76 \%$ in the Netherlands $(P=.138)$ and psychological distress in 59\% and 36\%, respectively $(P<.001)$. As judged by the GP, the most distressing symptoms were lack of energy (Belgium, 73\%; the Netherlands, 71\%) and lack of appetite (Belgium, 61\%; the Netherlands, 53\%). The difference in psychological distress, as judged by the GPs, remained after adjustment for differences in sex, age, and place of death (OR, 2.66). We additionally controlled for the occurrences of patient contact in the last week of life and prevalence of communication about psychological problems in the last month of life as possible confounders, but this did not alter the results.

\section{[TABLE 5. ]}

Congruence between the preferred and actual place of death was reached in $71 \%$ of Belgian and in $88 \%$ of Dutch patients $(P=.004)$. The chances of dying in the place of choice were three times lower in Belgium than in the Netherlands (OR, 0.31).

\section{DISCUSSION}

In both countries, more than $90 \%$ of patients were able to live at home for most of the time during their last year of life, had a palliative treatment goal in the last week of life, and discussed one or more end-oflife issues with their GP during the last months of life. During the last week of life, two thirds of patients 
Meeussen, K., Block, L. van den, Echteld, M.A., Boffin, N., Bilsen, J., Casteren, V. van, Abarshi, E., Donken, G Onwuteaka-Philipsen, B., Deliens, L. End-of-life care and circumstances of death in patients dying as a result of cancer in Belgium and the Netherlands: a retrospective comparative study. Journal of Clinical Ondably 2011, 29(32), 4327-4334

were bedridden, and the majority experienced distress from at least one physical symptom. Several aspects of care and dying were found to be related to country.

Data were collected via existing representative national GP networks to provide a nationwide general practice cancer population irrespective of care setting. The networks had been operational for many years and were registering a wide variety of health-related problems before end-of-life care was added. Other strengths of the study include the quality of the data collection procedures ${ }^{27}$ and the fact that the 2008 registration form used was developed simultaneously and in close collaboration between countries specifically for the purpose of cross-national comparability.

The study has several limitations. First, a retrospective study design may induce some bias. GPs might have overestimated some aspects of their caregiving (eg, the level of communication) or underestimated some aspects (eg, symptom distress) because of their awareness of what is socially desirable or of the difficulties of making a retrospective judgment of their own intentions, and these tendencies might differ between countries; however, most of the questions relate to an objective description of the patient's last phase of life. GPs may also have lacked the required information or recalled it incorrectly or did not consult the patient's medical record. The chances of this were reduced by the collection of data on a weekly basis, leaving little time between death and registration, and by instructing the GP to use patient files as much as possible. Second, some bias due to a GP's particular interest cannot be entirely excluded. Third, full nationwide representativeness could not be guaranteed in the Netherlands for nursing home deaths because GPs are not involved in care in these settings. However, given the high involvement of the GP in end-of-life care in both countries, ${ }^{14-16}$ the largely non-cancer population in Dutch nursing homes, ${ }^{39,59-61}$ the adjustment for place of death in our analyses, and the representativeness of the sample (if nursing home deaths are excluded), the results provide valuable insights into the manner in which the general population of patients with cancer die in Belgium and the Netherlands.

The results of this study show similarities as well as differences between the end of life of patients with cancer in Belgium and the Netherlands. Notwithstanding that more than $90 \%$ of patients were able to live at home for most of the time during the last year of life in both countries, a substantial proportion in both Belgium (29\%) and the Netherlands (19\%) die in a hospital. As we know, terminally ill patients with cancer prefer to be cared for at home and also to die there ${ }^{62-64}$; hence, the latter result might be a cause for concern for both practice and policy. However, the problem of death in a hospital seems most obvious in Belgium, and the contrast might be related to government and palliative care policies that, in the Netherlands, are more clearly geared toward encouraging death at home ${ }^{5,60}$ and also to differences between primary care cultures. In both countries, GPs occupy a prominent position in the provision of palliative care, ${ }^{26,65}$ but their specific roles at the end of life are different. Being gatekeepers to the health care system, Dutch GPs take on most care tasks themselves, although Belgian GPs seem more often to pursue a coordinating role only. ${ }^{25,26,66}$ This hypothesis is further supported by the finding that palliative care services are more likely to be used in general practice in Belgium than in the Netherlands, and by the differences in numbers of patient contacts in the last phase of life, especially during the last week.

The higher prevalence of end-of-life patient-GP conversations during the last month of life in the Netherlands compared with Belgium might also be related to the differences in medical culture. Ideas of candor and open communication might be valued more highly in the Netherlands, ${ }^{26}$ which could also partly explain the variation in the GP's knowledge of their patients' preferences about medical end-of-life treatment (43\% in Belgium $v 67 \%$ in the Netherlands).

Notwithstanding these differences, there are several similarities as well. In both countries, GPs focus more on physical and psychological than on spiritual or social issues; it may be that GPs feel less comfortable in introducing these topics, that other professionals may fulfill this task, or that these issues do not concern patients as much as others do. Options for palliative care were principally discussed during conversations held in the last month of life rather than earlier when the subject was addressed by fewer than half the patients; this is somewhat surprising, given the strong emphasis the palliative care movement places on advocating early communication and advance care planning and the relatively predictable disease trajectory of patients with cancer. ${ }^{2,67,68}$

From its beginnings, palliative care has predominantly focused on cancer care, and our results show the deep penetration of palliative care into end-of-life care for patients with cancer in both of the countries studied. ${ }^{1}$ Although a palliative care approach was present for most patients, many experienced symptom distress at the very end of life. Lack of energy and lack of appetite occurred as the most distressing physical 
Meeussen, K., Block, L. van den, Echteld, M.A., Boffin, N., Bilsen, J., Casteren, V. van, Abarshi, E., Donken, G Onwuteaka-Philipsen, B., Deliens, L. End-of-life care and circumstances of death in patients dying as a result of cancer in Belgium and the Netherlands: a retrospective comparative study. Journal of Clinical Ondälbyy: 2011, 29(32), 4327-4334

symptoms in a majority of patients. Pain was reported far less often as having caused distress, which might indicate that pain is a symptom that can be alleviated by palliative care, although other symptoms are far more challenging. However, pain was still a distressing symptom in more than $20 \%$ of patients with cancer in both countries, which suggests that there is potential for improvement in alleviating pain at the end of life.

In conclusion, the use of a nationwide sentinel network of GPs can provide important insights into how patients with cancer in general are dying in a particular country. It can also make comparison between countries possible. Although place of death and communication on end-of-life issues differ substantially between Belgium and the Netherlands, a palliative treatment goal has been adopted for the vast majority of patients in both countries. However, GPs report that the majority of patients with cancer still experience symptom distress at the end of life, which suggests important challenges for improving end-of-life care. Future research should also address other important aspects in the provision of end-of-life care, such as the well-being of families, and it should study more deeply the cause and effect of different health care approaches and their outcomes.

\section{ACKNOWLEDGMENT}

We thank Nathalie Bossuyt, MA, MD, for support with data collection and statistical advice; Jane Ruthven for editing the English version; and Rita De Boodt, Flemish Ministry of Welfare, Public Health and Family, for encoding the cause of death into International Classification of Diseases, 10th Revision (ICD-10) codes in the Belgian sample. We also thank Marianne Heshusius of the Netherlands Institute for Health Services Research for supervising the data collection process and all participating sentinel general practitioners for providing the study data.

\section{FOOTNOTES}

- Supported by a grant from the Flemish government agency for Innovation by Science and Technology (Strategic Basic Research No. 050158). The Belgian Sentinel Network of General Practitioners is supported by the Flemish and Walloon Community of Belgium.

- The Fund for Scientific Research, the Research Council of the Vrije Universiteit Brussel, the Institute for the Promotion of Innovation by Science and Technology in Flanders, and the Flemish and Walloon Ministry of Welfare, Public Health and Family, did not have any role in the design and conduct of the study, collection, management, analysis, or interpretation of the data, or in the preparation, review, or approval of this manuscript. In Belgium, the study protocol and anonymity procedures were approved by the ethical review board of the University Hospital of the Vrije Universiteit Brussel. An approval from the Ethical Review Board was not required for this study in The Netherlands because of the nature of the data collection (postmortem). In both countries, patient anonymity was preserved, and physician confidentiality was maintained through the registration and data entry processes.

- Authors' disclosures of potential conflicts of interest and author contributions are found at the end of this article.

\section{REFERENCES}

World Health Organisation (2002) National Cancer Control Programmes: Policies and Managerial Guidelines (2nd edition) (World Health Organisation, Geneva, Switzerland).

Sepúlveda C, Marlin A, Yoshida T, et al.(2002) Palliative Care: The World Health Organization's global perspective. J Pain Symptom Manage 24:91-96.

Seow H, Snyder CF, Mularski RA, et al.(2009) A framework for assessing quality indicators for cancer care at the end of life. J Pain Symptom Manage 38:903-912.C

Teno JM, Lima JC, Lyons KD(2009) Cancer patient assessment and reports of excellence: Reliability and validity of advanced cancer patient perceptions of the quality of care. J Clin Oncol 27:1621-1626.

Cohen J, Houttekier D, Onwuteaka-Philipsen B, et al.(2010) Which patients with cancer die at home? A study of six European countries using death certificate data. J Clin Oncol 28:2267-2273. 
Meeussen, K., Block, L. van den, Echteld, M.A., Boffin, N., Bilsen, J., Casteren, V. van, Abarshi, E., Donken, $G$ Onwuteaka-Philipsen, B., Deliens, L. End-of-life care and circumstances of death in patients dying as a result of cancer in Belgium and the Netherlands: a retrospective comparative study. Journal of Clinical Ondably 2011, 29(32), 4327-4334

Mitchell SL, Teno JM, Miller SC, et al.(2005) A national study of the location of death for older persons with dementia. J Am Geriatr Soc 53:299-305.

Johnson VM, Teno JM, Bourbonniere M, et al.(2005) Palliative care needs of cancer patients in U.S. nursing homes. J Palliat Med 8:273-279.

McCarthy EP, Phillips RS, Zhong Z, et al.(2000) Dying with cancer: Patients' function, symptoms, and care preferences as death approaches. J Am Geriatr Soc 48(suppl 5):S110-S121.

Claessens MT, Lynn J, Zhong Z, et al.(2000) Dying with lung cancer or chronic obstructive pulmonary disease: Insights from SUPPORT—Study to Understand Prognoses and Preferences for Outcomes and Risks of Treatments. J Am Geriatr Soc 48(suppl 5):S146-S153.

Dow LA, Matsuyama RK, Ramakrishnan V, et al.(2010) Paradoxes in advance care planning: The complex relationship of oncology patients, their physicians, and advance medical directives. J Clin Oncol 28:299_ 304.

Mack JW, Weeks JC, Wright AA, et al.(2010) End-of-life discussions, goal attainment, and distress at the end of life: Predictors and outcomes of receipt of care consistent with preferences. J Clin Oncol 28:12031208.

Hui D, Con A, Christie G, et al.(2009) Goals of care and end-of-life decision making for hospitalized patients at a Canadian tertiary care cancer center. J Pain Symptom Manage 38:871-881.

Zhang B, Wright AA, Huskamp HA, et al.(2009) Health care costs in the last week of life: Associations with end-of-life conversations. Arch Intern Med 169:480-488.

Bayingana K, Demarest S, Gisle L, et al.Health survey interview, Belgium 2004. Scientific Institute of Public Health Belgium, Department of Epidemiology, 2006, Report No. Depotn: D/2006/2505/4, IPH/EPI REPORTS No. 2006-035.

Donker GA(2007) Continue Morbiditeits Registratie Peilstations Nederland [in Dutch] (NIVEL, Utrecht, the Netherlands).

de Vogel-Voogt E, van der Heide A, van Leeuwen AF, et al.(2007) Patient evaluation of end-of-life care. Palliat Med 21:243-248.

Abarshi E, Onwuteaka-Philipsen B, Donker G, et al.(2009) General practitioner awareness of preferred place of death and correlates of dying in a preferred place: A nationwide mortality follow-back study in the Netherlands. J Pain Symptom Manage 38:568-577.

Abarshi E, Echteld M, Van den Block L, et al.(2010) Transitions between care settings at the end of life in the Netherlands: Results from a nationwide study. Palliat Med 24:166-174.

Meeussen K, Van den Block L, Bossuyt N, et al.(2009) GPs' awareness of patients' preference for place of death. Br J Gen Pract 59:665-670.

Van den Block L, Deschepper R, Bilsen J, et al.(2007) Transitions between care settings at the end of life in Belgium. JAMA 298:1638-1639.

Van den Block L, Deschepper R, Bossuyt N, et al.(2008) Care for patients in the last months of life: The Belgian Sentinel Network Monitoring End-of-Life Care study. Arch Intern Med 168:1747-1754.

Van den Block L, Deschepper R, Bilsen J, et al.(2009) Euthanasia and other end of life decisions and care provided in final three months of life: Nationwide retrospective study in Belgium. BMJ 339:b2772.

Van den Block L, Deschepper R, Bilsen J, et al.(2009) Euthanasia and other end-of-life decisions: A mortality follow-back study in Belgium. BMC Public Health 9:79.

Policy Department Economic and Scientific PolicyPalliative Care in the European Union, IP/A/ENVI/ST/2007-22, 2008, http://www.europarl.europa.eu.proxy.library.uu.nl/activities/committees/studies/download.do?file=21421. Abarshi E, Echteld MA, Van den Block L, et al.(2011) Use of palliative care services and general practitioner visits at the end of life in The Netherlands and Belgium. J Pain Symptom Manage 41:436448.

Griffiths J, Weyers H, Adams M(2008) Euthanasia and Law in Europe (Hart Publishing, Portland, OR). Van den Block L, Van Casteren V, Deschepper R, et al.(2007) Nationwide monitoring of end-of-life care via the Sentinel Network of General Practitioners in Belgium: The research protocol of the SENTI-MELC study. BMC Palliat Care 6:6.

Devroey D, Van Casteren V, Buntinx F(2003) Registration of stroke through the Belgian sentinel network and factors influencing stroke mortality. Cerebrovasc Dis 16:272-279.

Donker GA, Fleming DM, Schellevis FG, et al.(2004) Differences in treatment regimes, consultation frequency and referral patterns of diabetes mellitus in general practice in five European countries. Fam Pract 21:364-369.

Fleming DM, Schellevis FG, Van Casteren V(2004) The prevalence of known diabetes in eight European countries. Eur J Public Health 14:10-14. 
Meeussen, K., Block, L. van den, Echteld, M.A., Boffin, N., Bilsen, J., Casteren, V. van, Abarshi, E., Donken, G Onwuteaka-Philipsen, B., Deliens, L. End-of-life care and circumstances of death in patients dying as a result of cancer in Belgium and the Netherlands: a retrospective comparative study. Journal of Clinical Ondably 2011, 29(32), 4327-4334

Lobet MP, Stroobant A, Mertens R, et al.(1987) Tool for validation of the network of sentinel general practitioners in the Belgian health care system. Int J Epidemiol 16:612-618.

Eylenbosch WJ, Noah DStroobant A, Van Casteren V, Thiers G(1988) in Surveillance in Health and Disease, Surveillance systems from primary-care data: Surveillance through a network of sentinel general practitioners, eds Eylenbosch WJ, Noah D (Oxford University Press, Oxford, United Kingdom), pp 62-74. Wauters H, Van Casteren V, Buntinx F (2000) Rectal bleeding and colorectal cancer in general practice: Diagnostic study. BMJ 321:998-999.

Bossuyt N, Van Casteren V(2007) Epidemiology of suicide and suicide attempts in Belgium: Results from the sentinel network of general practitioners. Int J Public Health 52:153-157.

Cohen J, Bilsen J, Hooft P, et al.(2006) Dying at home or in an institution using death certificates to explore the factors associated with place of death. Health Policy 78:319-329.

Gielen B, Remacle A, Mertens R(2010) Patterns of health care use and expenditure during the last 6 months of life in Belgium: Differences between age categories in cancer and non-cancer patients. Health Policy 97:53-61.

Donker GA(2008) Continuous Morbidity Registration at Dutch Sentinel General Practice Network (Netherlands Institute for Health Services Research, Utrecht, the Netherlands).

Boffin N, Bossuyt N, Van Casteren VWetenschappelijk Instituut Volksgezondheid, Kenmerken van de peilartsen en hun praktijk; Situatie in 2007 en vergelijking met voorgaande jaren. http://www.wivisp.be/epidemio/epinl/medvnl/profil_07.pdf.

Hoek JF, Ribbe MW, Hertogh CM, et al.(2003) The role of the specialist physician in nursing homes: The Netherlands' experience. Int J Geriatr Psychiatry 18:244-249.

Seow H, Snyder CF, Shugarman LR, et al.(2009) Developing quality indicators for cancer end-of-life care: Proceedings from a national symposium. Cancer 115:3820-3829.

Casarett DJ, Teno J, Higginson I(2006) How should nations measure the quality of end-of-life care for older adults? Recommendations for an international minimum data set. J Am Geriatr Soc 54:1765-1771.

Emanuel EJ, Emanuel LL(1998) The promise of a good death. Lancet 351(suppl 2):SII21-SII29.

Lunney JR, Foley KM, Smith TJ, et al., eds (2003) Describing Death in America: What We Need to Know

(The National Academies Press, Washington, DC).

Rosenfeld K, Wenger NS(2000) Measuring quality in end-of-life care. Clin Geriatr Med 16:387-400.

Singer PA, Martin DK, Kelner M(1999) Quality end-of-life care: Patients' perspectives. JAMA 281:163-168.

Steinhauser KE, Clipp EC, McNeilly M, et al.(2000) In search of a good death: Observations of patients, families, and providers. Ann Intern Med 132:825-832.

Steinhauser KE, Christakis NA, Clipp EC, et al.(2000) Factors considered important at the end of life by patients, family, physicians, and other care providers. JAMA 284:2476-2482.

Stewart AL, Teno J, Patrick DL, et al.(1999) The concept of quality of life of dying persons in the context of health care. J Pain Symptom Manage 17:93-108.

Teno JM, Clarridge BR, Casey V, et al.(2004) Family perspectives on end-of-life care at the last place of care. JAMA 291:88-93.

Wenger NS, Rosenfeld K(2001) Quality indicators for end-of-life care in vulnerable elders. Ann Intern Med 135:677-685.

Pasman HR, Brandt HE, Deliens L, et al.(2009) Quality indicators for palliative care: A systematic review. J Pain Symptom Manage 38:145-156.

Van den Block L, Deschepper R, Drieskens K, et al.(2007) Hospitalisations at the end of life: Using a sentinel surveillance network to study hospital use and associated patient, disease and healthcare factors. BMC Health Serv Res 7:69.

Cartwright C, Onwuteaka-Philipsen BD, Williams G, et al.(2007) Physician discussions with terminally ill patients: A cross-national comparison. Palliat Med 21:295-303.

Teno JM(2010) Toolkit of Instruments to Measure End-of-life Care (Center for Gerontology and Health Care Research, Brown Medical School), wwwchcrbrownedu/pcoc/Choosing htm.

Hickman SE, Tilden VP, Tolle SW(2001) Family reports of dying patients' distress: The adaptation of a research tool to assess global symptom distress in the last week of life. J Pain Symptom Manage 22:565574.

Oken MM, Creech RH, Tormey DC, et al.(1982) Toxicity and response criteria of the Eastern Cooperative Oncology Group. Am J Clin Oncol 5:649-655.

Bilsen J, Cohen J, Chambaere K, et al.(2009) Medical end-of-life practices under the euthanasia law in Belgium. N Engl J Med 361:1119-1121.

van der Heide A, Onwuteaka-Philipsen BD, Rurup ML, et al.(2007) End-of-life practices in the Netherlands under the Euthanasia Act. N Engl J Med 356:1957-1965. 
Meeussen, K., Block, L. van den, Echteld, M.A., Boffin, N., Bilsen, J., Casteren, V. van, Abarshi, E., Donken, $G$ Onwuteaka-Philipsen, B., Deliens, L. End-of-life care and circumstances of death in patients dying as a result of cancer in Belgium and the Netherlands: a retrospective comparative study. Journal of Clinical OndDIbby: 2011, 29(32), 4327-4334

Brandt HE, Deliens L, Ooms ME, et al.(2005) Symptoms, signs, problems, and diseases of terminally ill nursing home patients: A nationwide observational study in the Netherlands. Arch Intern Med 165:314320.

Hoek JF, Penninx BW, Ligthart GJ, et al.(2000) Health care for older persons, a country profile: The Netherlands. J Am Geriatr Soc 48:214-217.

Ribbe MW, Ljunggren G, Steel K, et al.(1997) Nursing homes in 10 nations: A comparison between countries and settings. Age Ageing 26(suppl 2):3-12.

Higginson IJ, Sen-Gupta GJ (2000) Place of care in advanced cancer: A qualitative systematic literature review of patient preferences. J Palliat Med 3:287-300.

Tang ST(2003) When death is imminent: Where terminally ill patients with cancer prefer to die and why. Cancer Nurs 26:245-251.

Beccaro M, Costantini M, Giorgi Rossi P, et al.(2006) Actual and preferred place of death of cancer patients: Results from the Italian Survey of the Dying of Cancer (ISDOC) J Epidemiol Community Health 60:412-416.

Rocafort J, Centeno C (2008) EAPC Review of Palliative Care in Europe (EAPC, Milan, Italy).

Nederlands Huisartsen Genootschap(2009) NHG-Standpunt Toekomstvisie Huisartsenzorg 2012 [in Dutch] Huisarts en Palliatieve Zorg.

Lunney JR, Lynn J, Foley DJ, et al.(2003) Patterns of functional decline at the end of life. JAMA 289:23872392.

Radbruch L, Payne S, Board of Directors of the European Association for Palliative Care(2009) White Paper on standards and norms for hospice and palliative care in Europe: Part 1. Recommendations from the European Association for Palliative Care. Eur J Palliat Care 16:278-289. 
Meeussen, K., Block, L. van den, Echteld, M.A., Boffin, N., Bilsen, J., Casteren, V. van, Abarshi, E., Donken, G Onwuteaka-Philipsen, B., Deliens, L. End-of-life care and circumstances of death in patients dying as a result of cancer in Belgium and the Netherlands: a retrospective comparative study. Journal of Clinical OndDIbyy: 2011, 29(32), 4327-4334

\section{TABLES}

Table 1. Important Domains in End-of-Life Care Assessed in This Study

Medical care processes at the end of life

Number of general practitioner (GP)-patient encounters in the final 3 months of life (or encounters between GP and patient's relatives, regarding the patient)

Transitions, if any, between care settings in the final 3 months of life In case of hospital death, the moment of admission

Patient's main treatment goal in the last week of life (cure, prolonging life, palliation)

Involvement of specialist palliative care services. In the Netherlands: a GP with palliative care training, team with a palliative care consultant (trained nurse or physician), hospital-based palliative units, nursing home-based palliative care units, and hospice day care facility. In Belgium: multidisciplinary palliative support home care teams, hospitalbased mobile support teams, hospital-based palliative care units, palliative day care centers, and care home-based palliative care reference nurses

Palliative care services were considered to have been used if at least one service had been used during the last 3 months of life

Communication processes at the end of life

Content of the GP-patient conversations in the last month of life and before (about primary diagnosis, incurability of illness, life expectation, possible medical complications, physical symptoms, psychological problems [eg, sadness, worry, fear], social problems [eg, relationship problems, lack of social support, family not accepting the situation], spiritual problems [eg, difficulty in accepting situation, trouble with the meaning of life, angry at God], options for palliative care, burden of treatments)

Whether the patient had ever expressed wishes about any medical treatment that he or she would or would not want in the final phase of life and about the place of death

Circumstances of dying

Functional status during the last week of life using the Eastern Cooperative Oncology Group (ECOG) performance status scale: 0 , fully active; 1 , ambulatory, capable of work of a light nature; 2 capable of self-care but not work; 3 , in bed $\geq 50 \%$ of the time, capable of only limited self-care; 4 , completely bedridden, incapable of self-care

Whether the patient was in a coma or unconscious until death and, if so, for how long. Physical and psychological symptom distress during the last week of life was measured by the Memorial Symptom Assessment Scale-Global Distress Index (MSAS-GDI). GPs were asked whether the patient had the following symptoms during the last week of life (yes, no, unknown): lack of appetite, lack of energy, pain, feeling drowsy, constipation, dry mouth, difficulty breathing (physical symptoms); feeling sad, worrying, feeling irritable, feeling nervous (psychological symptoms). If yes, GPs were asked how much symptom distress the patient experienced (not at all, a little bit, somewhat, quite a bit, very much, unknown) for physical symptoms and how often a symptom occurred (rarely, occasionally, frequently, almost constantly, unknown) for psychological symptoms

Psychological symptoms were considered to have caused distress if patients appeared to feel this way "frequently" or "almost constantly" during the last week of life. Physical symptoms were considered to have caused distress if symptoms distressed the patient "quite a bit" or "very much." Symptoms that were not present were considered to have caused no distress. The GDI was calculated as the mean of the item scores for all physical and psychological symptoms; patients for whom no answer was given on more than three symptom items were not included in this calculation ${ }^{55}$

Whether the patient died at the place wished 
Meeussen, K., Block, L. van den, Echteld, M.A., Boffin, N., Bilsen, J., Casteren, V. van, Abarshi, E., Donken, G Onwuteaka-Philipsen, B., Deliens, L. End-of-life care and circumstances of death in patients dying as a result of cancer in Belgium and the Netherlands: a retrospective comparative study. Journal of Clinical OndDIbby: 2011, 29(32), 4327-4334

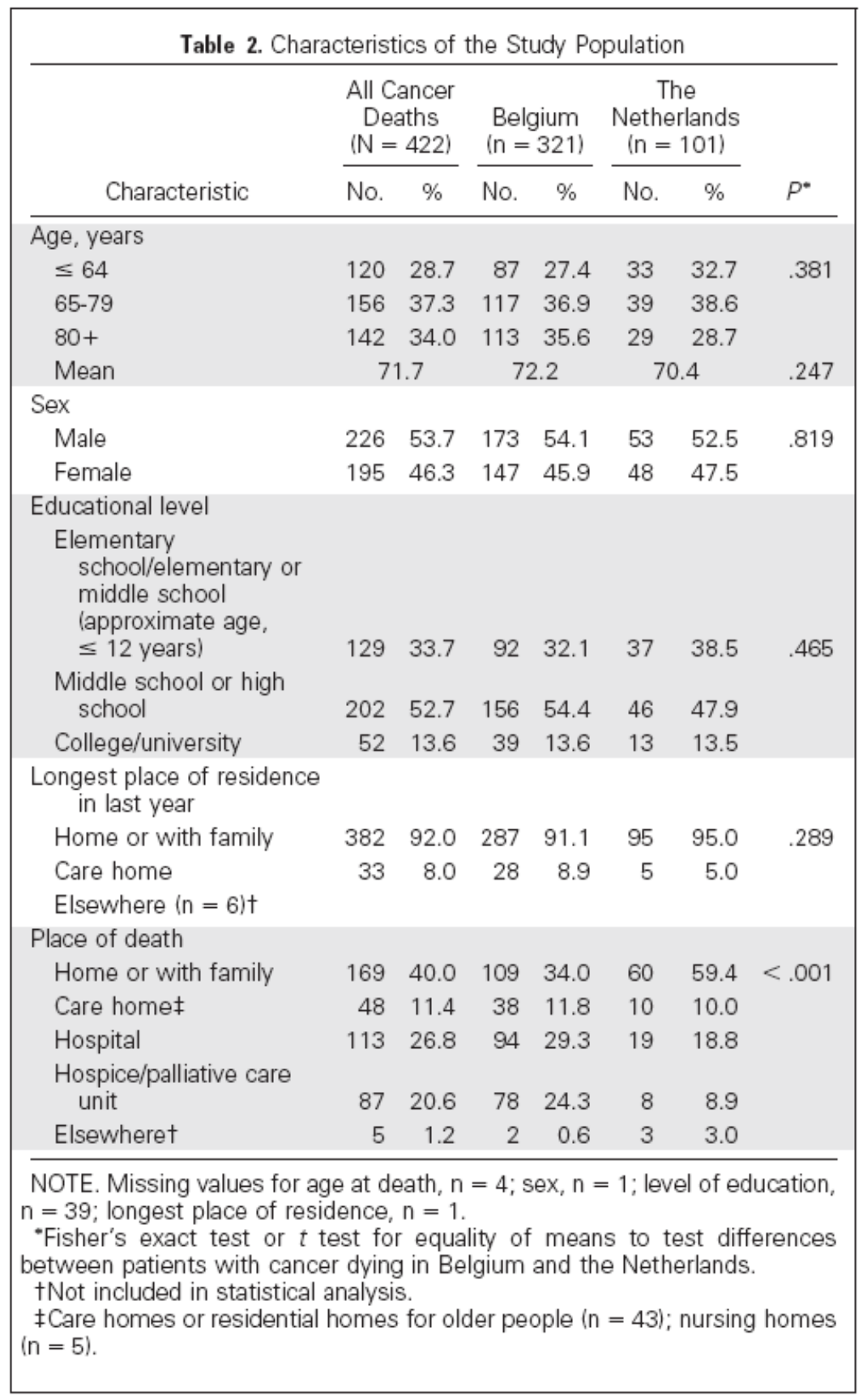


Meeussen, K., Block, L. van den, Echteld, M.A., Boffin, N., Bilsen, J., Casteren, V. van, Abarshi, E., Donken, G Onwuteaka-Philipsen, B., Deliens, L. End-of-life care and circumstances of death in patients dying as a result of cancer in Belgium and the Netherlands: a retrospective comparative study. Journal of Clinical OndDibby: 2011, 29(32), 4327-4334

\begin{tabular}{|c|c|c|c|c|c|c|c|c|c|}
\hline \multirow[b]{2}{*}{ Characteristic } & \multicolumn{2}{|c|}{$\begin{array}{l}\text { All Cancer } \\
\text { Deaths } \\
(\mathrm{N}=422)\end{array}$} & \multicolumn{2}{|c|}{$\begin{array}{c}\text { Belgium } \\
(n=321\rangle\end{array}$} & \multicolumn{2}{|c|}{$\begin{array}{c}\text { The } \\
\text { Netherlands } \\
(n=101)\end{array}$} & \multirow{2}{*}{$\begin{array}{l}\text { Fisher's } \\
\text { Exact } P\end{array}$} & \multirow[b]{2}{*}{ OR* } & \multirow[b]{2}{*}{$95 \% \mathrm{Cl}$} \\
\hline & No. & $\%$ & No. & $\%$ & No. & $\%$ & & & \\
\hline \multicolumn{10}{|l|}{ During the last 3 months of life: } \\
\hline More than eight GP-patient contactst & 179 & 42.4 & 122 & 38.0 & 57 & 56.4 & .001 & 0.62 & 0.37 to 1.02 \\
\hline Transferred at least once between care settings & 250 & 61.1 & 209 & 66.3 & 41 & 43.6 & $<.001$ & 1.75 & 0.93 to 3.27 \\
\hline Palliative care services initiated & 265 & 62.9 & 231 & 72.0 & 34 & 34.0 & $<.001$ & 6.73 & 3.86 to 11.75 \\
\hline \multicolumn{10}{|l|}{ During last week of life: } \\
\hline One or more GP-patient contacts & 316 & 74.9 & 228 & 71.0 & 88 & 87.1 & .001 & 0.48 & 0.23 to 0.996 \\
\hline Transferred at least once between care settings & 82 & 20.0 & 70 & 22.2 & 12 & 12.8 & .056 & 1.52 & 0.71 to 3.28 \\
\hline Terminal hospital admission & 113 & 26.8 & 94 & 29.3 & 19 & 18.8 & .040 & $1.89 \ddagger$ & 1.08 to 3.30 \\
\hline Admission during last week ( $\mathrm{v}$ before last week) & 38 & 34.9 & 32 & 34.8 & 6 & 35.3 & 1.000 & 1.01 & 0.33 to 3.03 \\
\hline Palliative treatment goal ( $v$ curative/prolonging life) & 385 & 93.0 & 294 & 93.6 & 91 & 91.0 & .372 & 1.92 & 0.77 to 4.77 \\
\hline \multicolumn{10}{|c|}{$\begin{array}{l}\text { NOTE. Missing values for transfer between care setting, } n=13 \text {; timing of terminal hospital admission, } n=9 ; \text { treatment goal, } n=8 \text {; specialist palliative care } \\
\text { services involved, } n=1 \text {. } \\
\text { Abbreviations: GP, general practitioner; OR, odds ratio. } \\
\text { •From multivariate logistic regression models. For these analyses, we compared end-of-life care between patients with cancer from the Netherlands (reference } \\
\text { category) and those from Belgium while adjusting for differences in place of death, age, and sex. } \\
\text { †Dichotomized at its median value; the two groups differ in size because approximately } 10 \% \text { of patients had the median number of eight GP contacts. } \\
\text { †Not controlled for place of death in multivariate analysis. }\end{array}$} \\
\hline
\end{tabular}

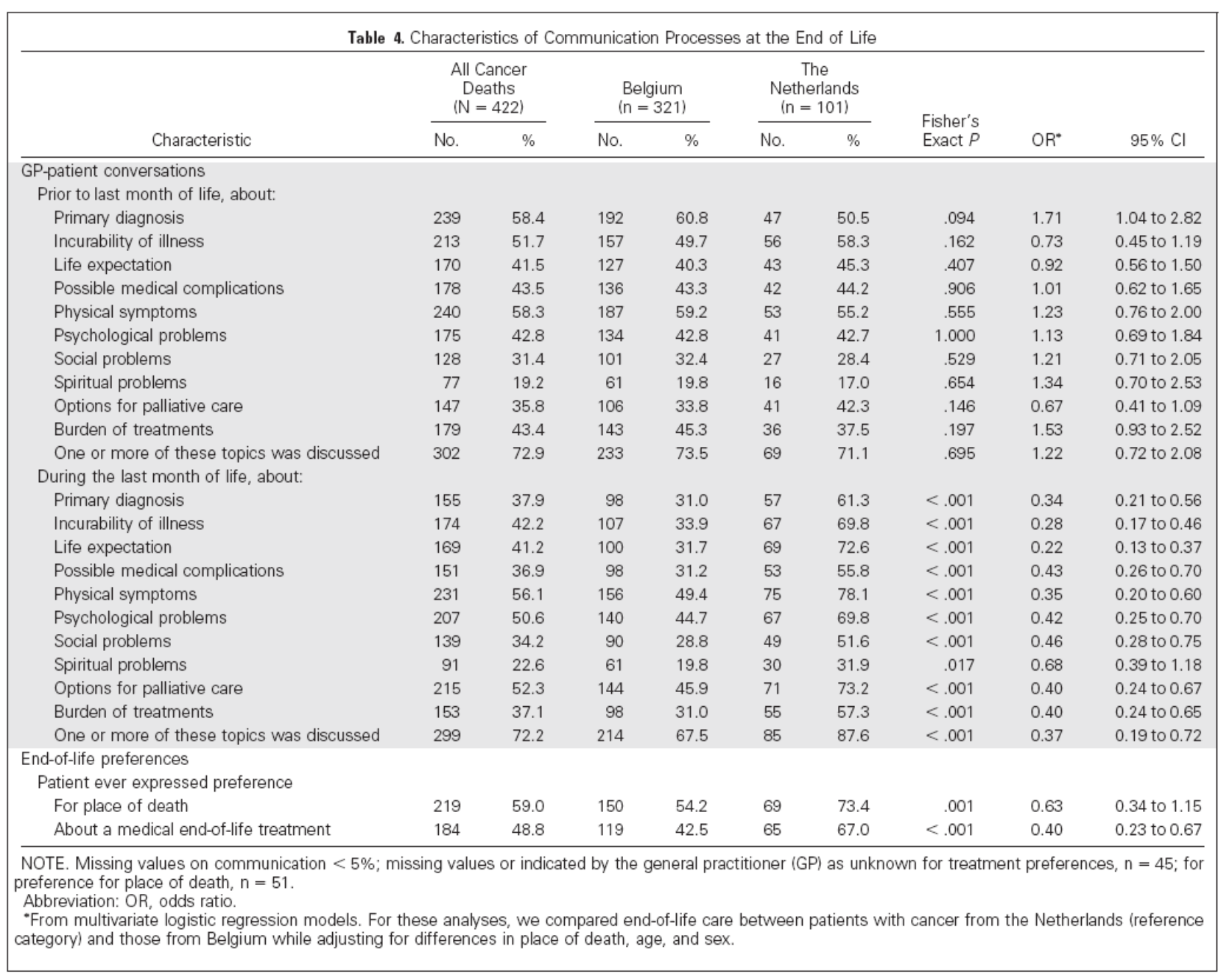


Meeussen, K., Block, L. van den, Echteld, M.A., Boffin, N., Bilsen, J., Casteren, V. van, Abarshi, E., Donken, G Onwuteaka-Philipsen, B., Deliens, L. End-of-life care and circumstances of death in patients dying as a result of cancer in Belgium and the Netherlands: a retrospective comparative study. Journal of Clinical OndDIbby: 2011, 29(32), 4327-4334

\begin{tabular}{|c|c|c|c|c|c|c|c|c|c|}
\hline \multirow[b]{2}{*}{ Variable } & \multicolumn{2}{|c|}{$\begin{array}{c}\text { All Cancer } \\
\text { Deaths } \\
(\mathrm{N}=422)\end{array}$} & \multicolumn{2}{|c|}{$\begin{array}{l}\text { Belgium } \\
(n=321)\end{array}$} & \multicolumn{2}{|c|}{$\begin{array}{l}\text { The } \\
\text { Netherlands } \\
\text { (n=101) }\end{array}$} & \multirow{2}{*}{$\begin{array}{l}\text { Fisher's } \\
\text { Exact } P\end{array}$} & \multirow[b]{2}{*}{ OR* } & \multirow[b]{2}{*}{$95 \% \mathrm{Cl}$} \\
\hline & No. & $\%$ & No. & $\%$ & No. & $\%$ & & & \\
\hline \multicolumn{10}{|l|}{ Clinical status in last week of life } \\
\hline Physically completely disabled and & 275 & 67.1 & 209 & 66.6 & 66 & 68.8 & .712 & 0.97 & 0.59 to 1.62 \\
\hline $\begin{array}{l}\text { One or more days unconsciousness } \\
\text { until death }\end{array}$ & 214 & 56.0 & 171 & 58.0 & 43 & 49.4 & .177 & 1.26 & 0.76 to 2.08 \\
\hline \multicolumn{10}{|l|}{$\begin{array}{l}\text { Physical symptom distress in last } \\
\text { week of life }\end{array}$} \\
\hline GP could make estimation $\neq$ & 362 & 85.8 & 282 & 87.9 & 80 & 79.2 & .034 & 3.58 & 1.76 to 7.13 \\
\hline Distress from at least one symptom & 297 & 82.0 & 236 & 83.7 & 61 & 76.3 & .138 & 1.59 & 0.84 to 3.02 \\
\hline Lack of appetite & 207 & 59.3 & 165 & 61.1 & 42 & 53.2 & .241 & 1.22 & 0.72 to 2.08 \\
\hline Lack of energy & 254 & 72.8 & 197 & 73.2 & 57 & 71.3 & .775 & 1.09 & 0.61 to 1.96 \\
\hline Pain & 80 & 23.2 & 61 & 23.0 & 19 & 23.8 & .881 & 0.98 & 0.52 to 1.87 \\
\hline Feeling drowsy & 98 & 28.9 & 82 & 31.7 & 16 & 20.0 & .049 & 1.77 & 0.92 to 3.39 \\
\hline Constipation & 34 & 11.0 & 29 & 12.7 & 5 & 6.3 & .147 & 2.37 & 0.85 to 6.64 \\
\hline Dry mouth & 63 & 20.4 & 52 & 22.5 & 11 & 14.1 & .143 & 1.59 & 0.75 to 3.37 \\
\hline Difficulty breathing & 86 & 25.3 & 74 & 28.5 & 12 & 15.0 & .018 & 2.14 & 1.04 to 4.39 \\
\hline \multicolumn{10}{|l|}{$\begin{array}{l}\text { Psychological symptom distress in last } \\
\text { week of life }\end{array}$} \\
\hline GP could make estimation $\ddagger$ & 322 & 76.3 & 244 & 76.0 & 78 & 77.2 & .893 & 0.35 & 0.10 to 1.22 \\
\hline Distress from at least one symptom & 172 & 53.4 & 144 & 59.0 & 28 & 35.9 & $<.001$ & 2.66 & 1.49 to 4.77 \\
\hline Feeling sad & 102 & 34.1 & 88 & 38.9 & 14 & 19.2 & .002 & 2.57 & 1.29 to 5.13 \\
\hline Worrying & 121 & 39.9 & 101 & 44.3 & 20 & 26.7 & .007 & 1.98 & 1.05 to 3.73 \\
\hline Feeling irritable & 41 & 13.4 & 37 & 15.9 & 4 & 5.3 & .019 & 3.85 & 1.28 to 11.58 \\
\hline Feeling nervous & 61 & 20.3 & 56 & 24.7 & 5 & 6.8 & .001 & 4.66 & 1.74 to 12.48 \\
\hline Global Distress Index (mean) & \multicolumn{2}{|c|}{1.25} & \multicolumn{2}{|c|}{1.32} & \multicolumn{2}{|c|}{1.04} & .001 & 2.97 & 1.62 to 5.50 \\
\hline Died at the place of wish§ & 167 & 76.3 & 106 & 70.7 & 61 & 88.4 & .004 & 0.31 & 0.14 to 0.71 \\
\hline \multicolumn{10}{|c|}{ 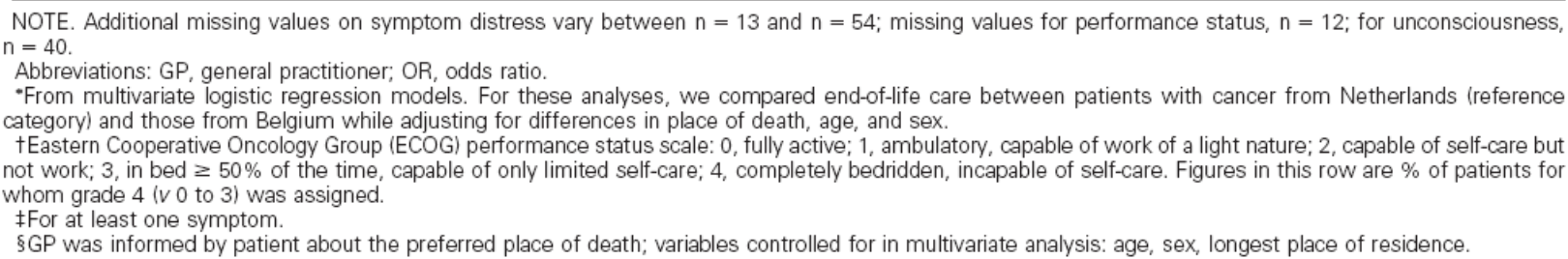 } \\
\hline
\end{tabular}

